\title{
Substrate Dependence in the Formation of Au Nanoislands for Plasmonic Platform Application
}

\author{
Marcin Łapiński ${ }^{1}$ (D) $\cdot$ Robert Kozioł $^{1} \cdot$ Anita Cymann $^{2} \cdot$ Wojciech Sadowski ${ }^{1} \cdot$ Barbara Kościelska $^{1}$
}

Received: 17 June 2019 / Accepted: 12 August 2019 / Published online: 22 August 2019

(C) The Author(s) 2019

\begin{abstract}
In this work, the influence of the various substrates on Au nanoisland formation has been studied. Nanostructures were obtained via annealing of thin $\mathrm{Au}$ films. In order to determine nanoisland formation mechanisms, correlation between an initial film thickness and temperature of formation, shapes, and dimensions of nanostructures was examined. For the surface morphology studies, nanograin structure, and chemical composition analysis, SEM, HR TEM, and EDS measurements were performed, respectively. Morphology studies showed that the temperature at which nanostructures form varies for different substrates, which indicates high impact of the substrate material on the nanostructure formation. In the case of silicon substrate, besides the phenomenon of spinodal dewetting, the effect of eutectics on the nanostructures was additionally taken into consideration.
\end{abstract}

Keywords Directional solidification $\cdot$ High-resolution electron microscopy (HREM) $\cdot$ Nanostructure $\cdot$ Scanning electron microscopy (SEM) $\cdot$ Thin-film annealing

\section{Introduction}

In recent years, much attention has been paid to the formation of noble metal nanostructures. This is mainly due to the possibility of using them as plasmonic platforms and nanosensors $[1,2]$. One of the most commonly used metals in plasmonic platforms is gold. In addition to the high concentration of free electrons, leading to a high plasma frequency and a negative real permittivity over a wide range of frequencies, gold is characterized by high chemical resistance, which greatly facilitates the process of producing platforms [3]. The frequency and intensity of the plasmon resonance are highly dependent not only on the material of the nanostructures but also on its size, shape, and morphology. There is also a strong correlation

Marcin Łapiński

marcin.lapinski@pg.edu.pl

$1 \quad$ Faculty of Applied Physics and Mathematics, Department of Solid State Physics, Gdansk University of Technology, Gabriela Narutowicza 11/12, 80-233 Gdansk, Poland

2 Faculty of Chemistry, Department of Chemical Apparatus and Theory of Machines, Gdansk University of Technology, Gabriela Narutowicza 11/12, 80-233 Gdansk, Poland with dielectric properties of surrounding medium [4-6]. One of the easiest methods for the production of metal nanostructures is the way that is based on the thermal annealing of thin metal films [7, 8]. It is well known that several processes could be responsible for the formation of the nanostructures within this technique. One of them is directional solidification of eutectics that is widely cited in the literature. It may occur in the case of the gold film that is deposited on a silicon substrate. The melting temperature of $\mathrm{Au}-\mathrm{Si}$ eutectic system drops to about $363{ }^{\circ} \mathrm{C}$ [9-12], so nanostructures can be formed in the temperatures much below the melting temperature of $\mathrm{Au}$. However, it can lead to phase non-homogeneity of the gold nanostructures [10,12-15]. On the other hand, in the cases of thin and ultra-thin layers, the leading process of nanostructure growths seems to be solid-state dewetting. It is widely discussed in the literature that the formation of nanostructures is based on nucleation of holes and their later growth [2, 16-19]. Nucleation can take place in two ways: as homogeneous nucleation, when holes appear as a consequence of small thermal density fluctuations. The second type is a heterogeneous nucleation, caused mainly by defects present or in the metal film or on the interface between the film and the substrate. Holes can be also created during the spinodal dewetting process, which occurs by the amplification of 
Fig. 1 SEM images of gold nanostructures on silicon substrate, with initial gold film of $10 \mathrm{~nm}$, annealed at $\mathbf{a} 300^{\circ} \mathrm{C}, \mathbf{b}$ $325^{\circ} \mathrm{C}$, c $350{ }^{\circ} \mathrm{C}$, d $375^{\circ} \mathrm{C}$, e $400{ }^{\circ} \mathrm{C}$, and $\mathbf{f} 425^{\circ} \mathrm{C}$

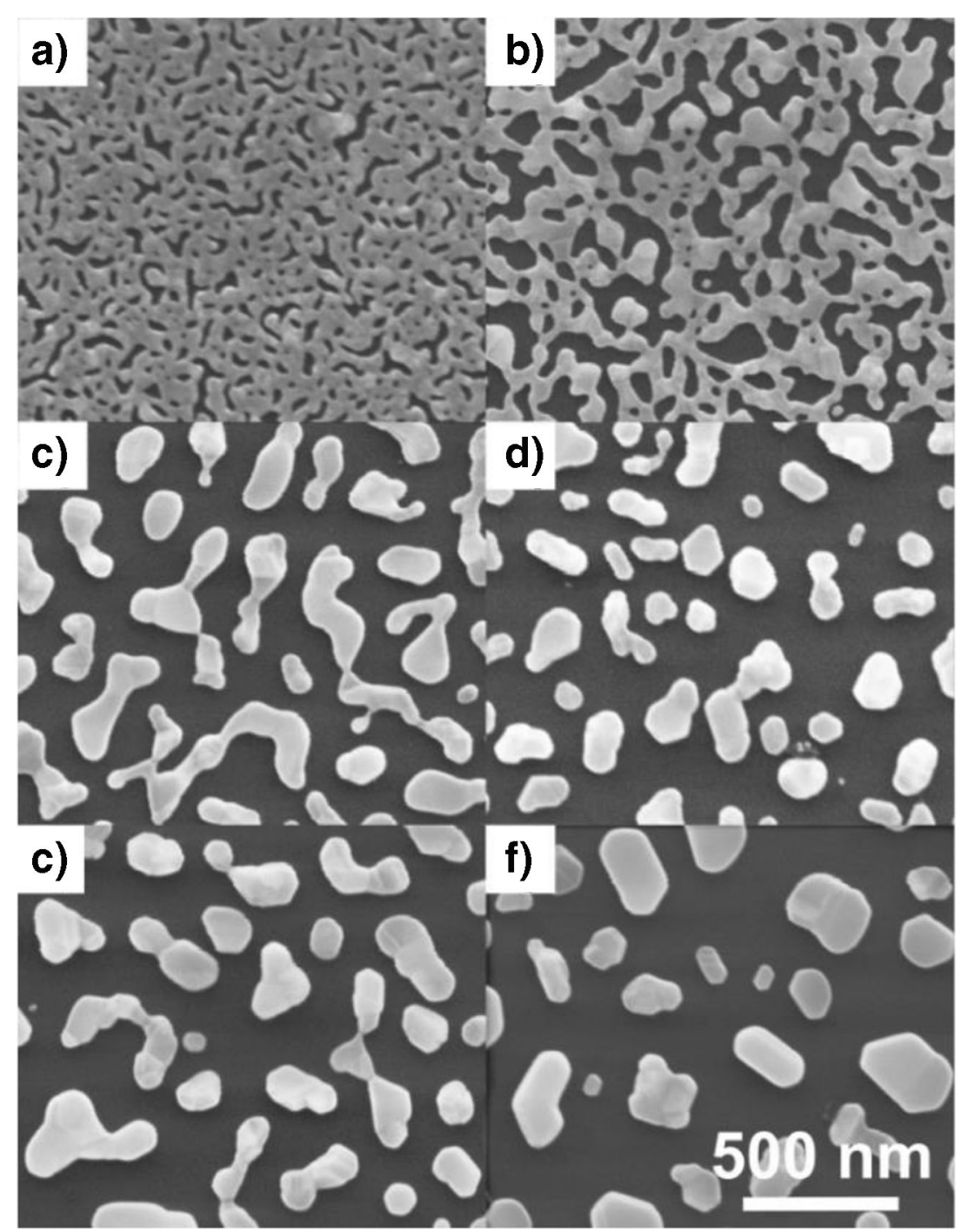

periodical film thickness fluctuation. In any case, dewetting occurs at temperatures well below the melting temperature of the film, so during this process the material remains in the solid state. It is difficult to determine experimentally which of the types of dewetting takes place in a specific case in the process of formation of metal nanostructures. Undoubtedly, the substrate plays a huge role here. It is also difficult to say whether the existence of eutectics has a significant impact on the formation of nanostructures at temperatures above the eutectic temperature, especially that the size of nanostructures or thin films greatly affects their melting point [20,21].

In our previous works [22, 23], we described the method of synthesis, structure, and electromagnetic field distribution of $\mathrm{Au}$ nanostructures that form plasmonic platforms. However, at that time, we could not decide which process was mainly responsible for the growth of nanostructures. Present research are focused on processes leading to the formation of nanostructures as a result of heating thin layers deposited on various substrates when the annealing temperature far exceeds the temperature at which dewetting starts.

\section{Experimental}

Au nanostructures were prepared on quartz glass, $\mathrm{Si}(111)$, and well-polished Mo and Ta substrates. The substrates were cleaned with warm acetylacetone and then rinsed in ethanol. Thin Au films (with thickness in the range of 1-200 nm) were deposited using a tabletop dc magnetron sputtering coater (EM SCD 500, Leica) in pure Ar plasma condition (argon, 
Fig. 2 SEM images of gold nanostructures on tantalum substrate, with initial gold film of $10 \mathrm{~nm}$, annealed at a $300^{\circ} \mathrm{C}, \mathbf{b}$ $325^{\circ} \mathrm{C}, \mathbf{c} 350^{\circ} \mathrm{C}$, d $375^{\circ} \mathrm{C}$, e $400{ }^{\circ} \mathrm{C}$, and $\mathbf{f} 425^{\circ} \mathrm{C}$

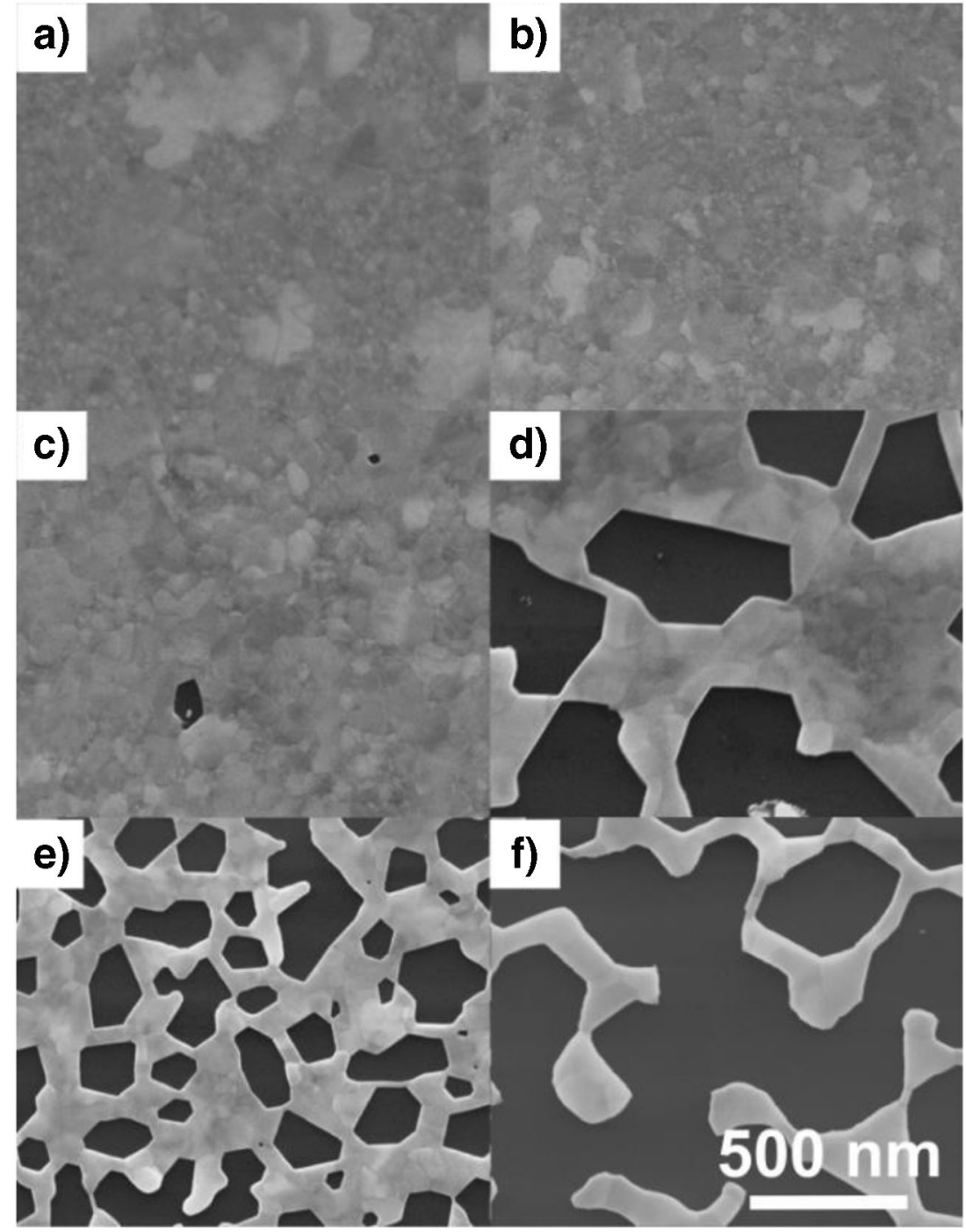

Air Products, 99.999\%). The Au target had $99.99 \%$ purity, the rate of $\mathrm{Au}$ layer deposition was about $0.4 \mathrm{~nm} / \mathrm{s}$, and incident power was in a range of $30-40 \mathrm{~W}$. The sputtering system was equipped with a quartz crystal microbalance for the film thickness in situ measurements. As prepared films of varying thicknesses were subsequently put to the hot furnace for formation of nanostructures. Samples were annealed at various temperatures in air atmosphere. To analyze the surface morphology of the samples, FEI Quanta FEG 250 scanning electron microscope (SEM) and Zeiss CrossBeam 540 SEM operated at $10 \mathrm{kV}$ and $2 \mathrm{kV}$, respectively, were used. For nanograin structure and chemical composition analyses, a TALOS F200X high-resolution transmission electron microscope (HR TEM) equipped with an EDS detector was used.

\section{Results and Discussion}

In Figs. 1 and 2, selected SEM images of nanostructures formed during annealing of 10-nm thin Au films at different temperatures are presented. The films were deposited on silicon (Fig. 1) and tantalum (Fig. 2) substrates. The heating temperature's as well as the substrate's influence on the formation of nanostructures is well visible. However, in both cases, the process of formation of nanostructures begins with ruptures in the layer. Then, holes are growing, initially irregular-shaped $\mathrm{Au}$ structures are formed, and finally, when the temperature increases, separated nanostructures are formed. The process looks similar for both substrates, but the temperature at which the nanostructures form is different. 
This indicates a high impact of the substrate material on the formation of nanostructures.

The influence of the initial Au film thickness on the temperature of formation of nanostructures on various substrates is shown in Fig. 3. The temperature of nanostructure formation was determined on the basis of SEM images. It was assumed that it is the temperature at which isolated islands are already completely formed, as is shown in Fig. 1d. Regardless of the type of substrate, the fastest temperature rise can be observed for very thin layers, with a thickness of up to $20 \mathrm{~nm}$. In the case of larger thicknesses of the initial layers, the impact on the temperature of formation of nanostructures is smaller. The main force leading to the nanostructures formation is the reduction of the surface energy. This process can be explained on the basis of the phenomenon of dewetting. It takes place well below the melting temperature of the given metal from which the layer is made and leads to formation of separated objects, like droplets, stripes, and pillars [24]. It can be concluded from the presented SEM images (Figs. 1 and 2) that in the case of the examined films, the phenomenon of spinodal dewetting is mainly responsible for nanostructure growth. In this process, ruptures in the layer appear spontaneously due to thermally activated surface waves. When the size of the holes reaches the critical size, the edges of holes start to be retracted; and in this way, nanostructures are formed, which was described in detail by Thompson [25]. We suggested in our previous works that this phenomenon can be mainly responsible for $\mathrm{Au}$ nanostructure growth on $\mathrm{Si}$ and quartz glass supports $[22,23]$. Of course, the impact of defects cannot be neglected either in the layer itself or on the interface between the layer and the substrate (heterogeneous dewetting) [25], especially when the substrate and the layer are created by various materials, with different crystalline structures. If nanoislands are formed as a result of spinodal dewetting, then the following relationship can be proposed between the thickness of the layer $(h)$ and the diameter of the nanostructure $(D)[26]$ :

$D=\left(\frac{24 \pi^{3} \gamma}{A f(\theta)}\right)^{1 / 3} h^{5 / 3}=C h^{5 / 3}$

where $f(\theta)$ is the geometric factor based on the particle contact angle $\theta, \gamma$ is the surface tension of the metal, and $A$ is the Hamaker constant. This relation was observed in many experimental studies $[26,27]$ and remains valid at the temperature at which the isolated islands appeared. However, very often, in order to obtain the optimal shape and size of nanostructures, the nanostructures are formed at much higher temperatures. The films, for whom the calculations of parameters are described by the above equation, were deposited on silicon substrate and annealed at $550{ }^{\circ} \mathrm{C}$ for $15 \mathrm{~min}$. Thermal conditions were chosen because of the plasmon resonance parameters of manufactured plasmonic platforms, which was studied in our previous works [22, 23]. The dependence of the island's diameter on the thickness of the initial layer for these conditions is presented in Fig. 4. In this case, the calculated exponent is equal to $2.60 \pm 0.02$ and significantly deviates from the value characteristic for spinodal dewetting. However, we are here far beyond the

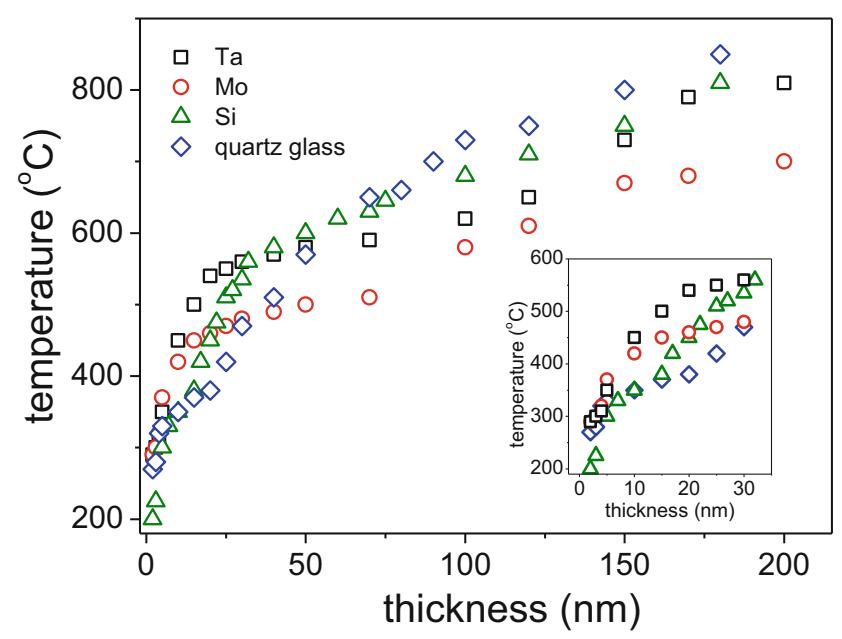

Fig. 3 The influence of film thickness on the temperature of formation of nanostructures. The smallest thickness of the layer from which the studies were started is $2 \mathrm{~nm}$

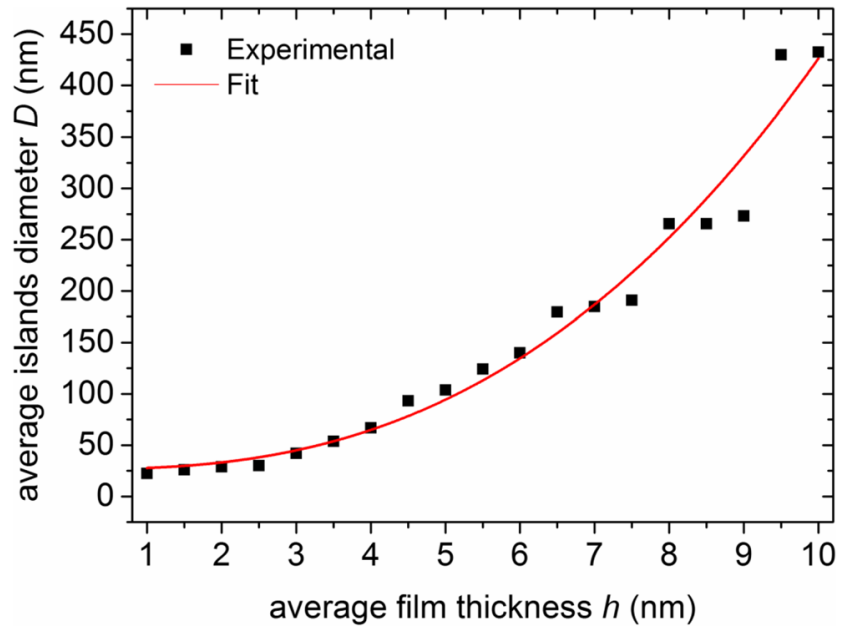

Fig. 4 The dependence of the island's diameter on the thickness of the initial film, calculated for $\mathrm{Au}$ films deposited on the silicon substrate. The films were annealed at $550{ }^{\circ} \mathrm{C}$ for $15 \mathrm{~min}$ 
Fig. 5 a HR TEM image of $2.8-$ $\mathrm{nm}$ thin film, annealed at $550{ }^{\circ} \mathrm{C}$ for $15 \mathrm{~min}$. b EDS analysis of the nanograin. $\mathbf{c}$ SEM image of the sample
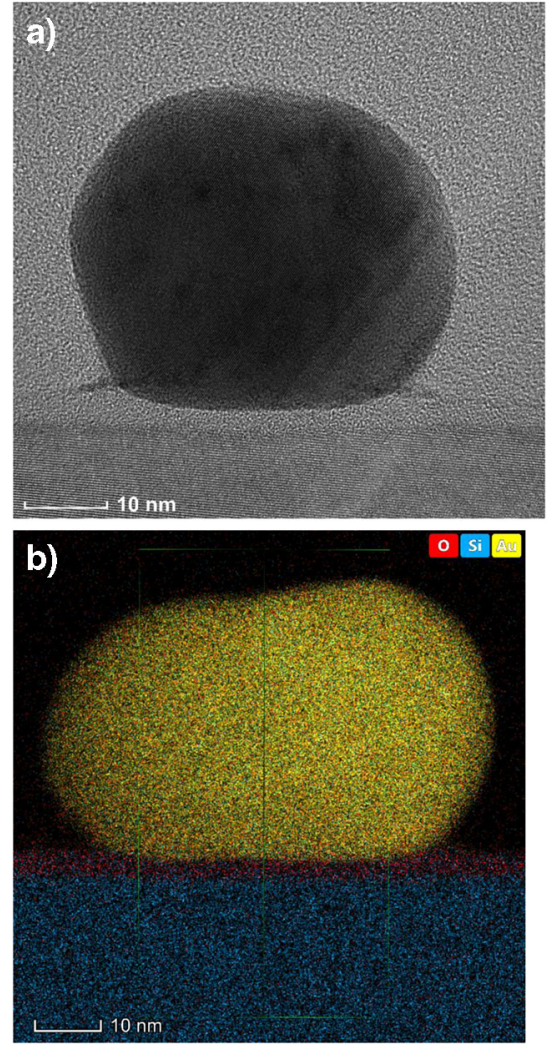

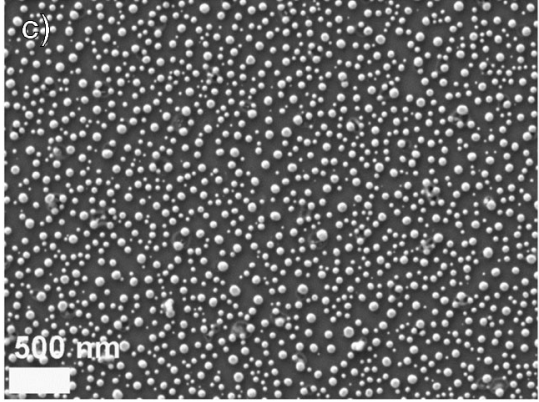

range in which nanostructures have already formed. It is also well above the eutectic temperature, which in the $\mathrm{Au}-$ $\mathrm{Si}$ system is around $363{ }^{\circ} \mathrm{C}$ [9-12]. Au-Si forms one of the simplest eutectic alloy; therefore, during cooling below the eutectic temperature, Au and Si crystallize into two different phases. As a result of that mechanism, heterogeneous nanostructures of Au containing Si phase inclusions are formed. Such nanostructures have been observed in several works describing directional solidification of $\mathrm{Au}-\mathrm{Si}$ eutectics [10, 13, 14, 28].

To explain the effect of eutectic on the formation of $\mathrm{Au}$ nanostructures on the Si substrate, HR TEM studies were carried out. The result for the sample annealed at $550{ }^{\circ} \mathrm{C}$ for $15 \mathrm{~min}$ is shown in Fig. 5. The initial film thickness was equal to $2.8 \mathrm{~nm}$. For clarity, the SEM image of the sample was added (Fig. 5c). As may be seen from EDS analysis, the nanograins are formed only by $\mathrm{Au}$ (Fig. 5b). It should be noted, however, that the annealing time is short in this case, which prevents the diffusion of $\mathrm{Au}$ by the native $\mathrm{SiO}_{2}$ layer and hence the formation of eutectics. $b$

The HR TEM image of a cross section of a nanoisland formed as a result of the heating of the Au layer of the same thickness for $60 \mathrm{~min}$ (Fig. 6) is completely different from that shown in Fig. 5. As can be seen, the silicon substrate under the nanograin has been melted. At annealing temperature of about $550{ }^{\circ} \mathrm{C}$, this can be only explained by the fact that as a result of $\mathrm{Au}$ to $\mathrm{Si}$ diffusion, eutectics between $\mathrm{Au}$ and Si was formed. Detailed EDS analysis of a cross section of a nanoisland annealed at $550^{\circ} \mathrm{C}$ for $15 \mathrm{~min}$ and $550^{\circ} \mathrm{C}$ for $60 \mathrm{~min}$ is shown in Fig. 7. It may be seen from Figs. $6 \mathrm{~b}$ and $7 \mathrm{~b}$ that no $\mathrm{Si}$ inclusions are visible in the Au nanostructure. On the other hand, such a situation as where a whole structure is made entirely of metal can take place in nanosized scale [29]. As shown in the presented HR TEM images, in the case of growth of nanostructures by thin-layer annealing, the substrate plays a huge role. This should be taken into account especially when looking for optimal structures for applications, e.g., in plasmonic platforms.

\section{Conclusions}

This paper presents the formation of Au nanostructures on various substrates, like quartz glass, Si, Mo, and Ta. Nanostructures were grown as a result of annealing of thin Au films, with thicknesses in the range from 1 up to $200 \mathrm{~nm}$. 
Fig. 6 a HR TEM image of 2.8$\mathrm{nm}$ thin film, annealed at $550{ }^{\circ} \mathrm{C}$ for $60 \mathrm{~min}$. b EDS analysis of the nanograin. $\mathbf{c}$ SEM image of the sample
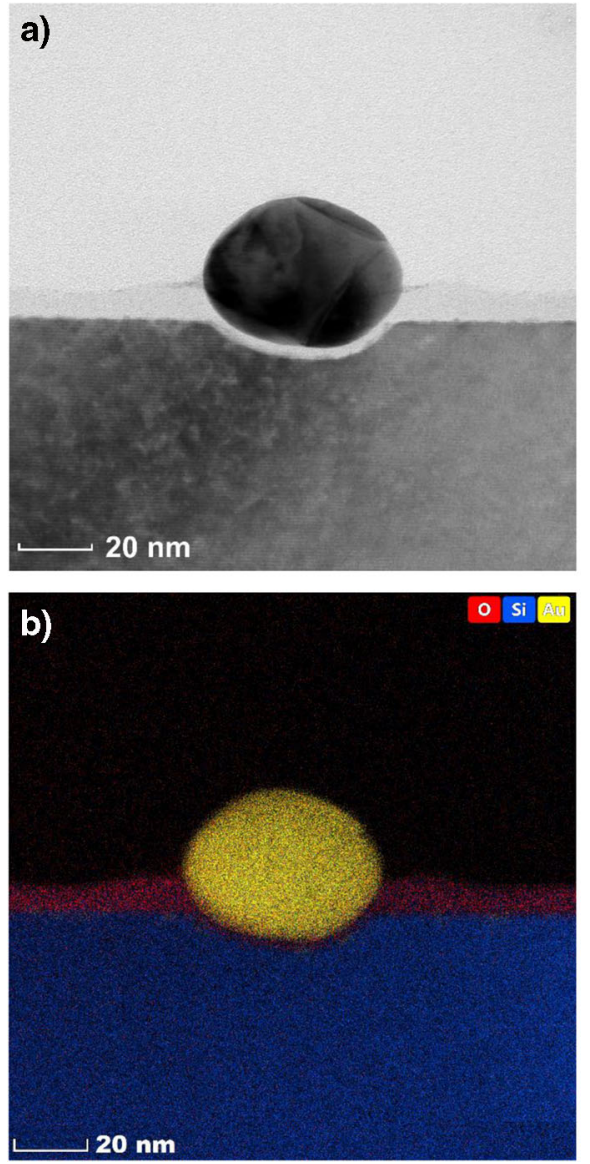

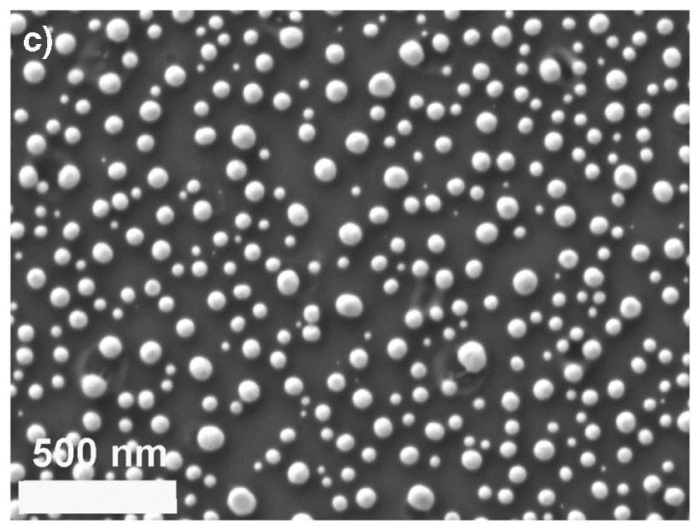

In the case of silicon substrate, the effect of eutectics on the growth of nanostructures was analyzed. As may be concluded from HR TEM results, when the annealing occurs at temperatures higher than the temperature of eutectics, besides the phenomenon of solid-state dewetting, directional solidification of eutectics should be also considered in the process of nanostructure formation, especially in the case of a long annealing time when the atoms of metals have

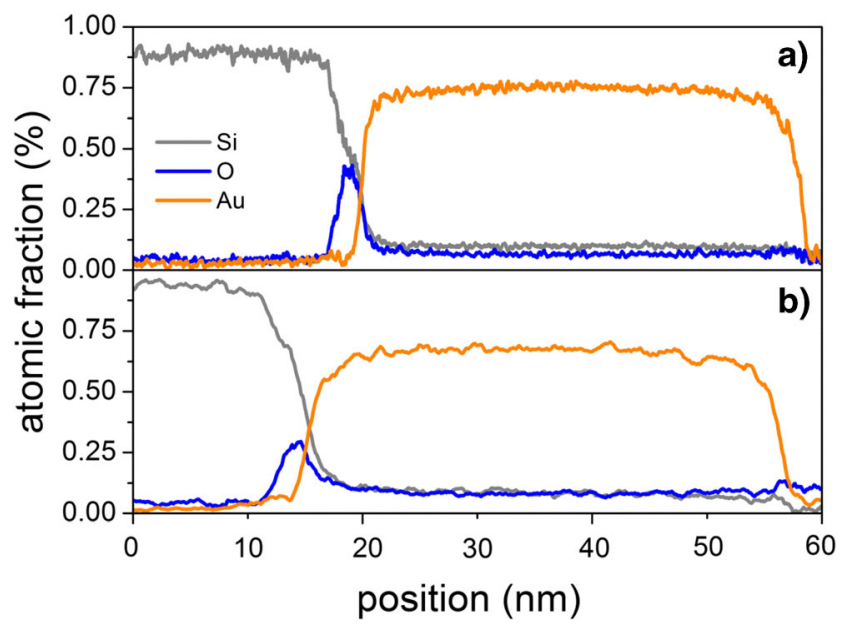

Fig. 7 EDS analysis of cross section of a nanoisland annealed at a $550{ }^{\circ} \mathrm{C}$ for $10 \mathrm{~min}$ and $\mathbf{b} 550{ }^{\circ} \mathrm{C}$ for $60 \mathrm{~min}$ enough time for diffusion into the substrate. It should also be emphasized that in the case of thin layers, the melting point of the material is reduced in relation to the bulk material. Certainly, in the annealing process, at temperatures higher than characteristic for the phenomenon of dewetting, it will affect the shape and size of the nanostructures.

Funding Information This research was supported by the grant 2017/01/ X/ST5/01000 financed by National Science Centre (MŁ).

Open Access This article is distributed under the terms of the Creative Commons Attribution 4.0 International License (http:// creativecommons.org/licenses/by/4.0/), which permits unrestricted use, distribution, and reproduction in any medium, provided you give appropriate credit to the original author(s) and the source, provide a link to the Creative Commons license, and indicate if changes were made.

\section{References}

1. Derkachova A, Kolwas K, Demchenko I (2016) Dielectric function for gold in plasmonics applications: size dependence of plasmon resonance frequencies and damping rates for nanosphere. Plasmonics 11:941-951. https://doi.org/10.1007/s11468-0150128-7

2. Yoo J, Kim J-H, Lee K, Lee S, Kim S, Park H-K, Kim S-W, Bae J, Park J-J, Choi D (2013) Dewetted gold nanoparticles on ZnO 
nanorods for three-dimensionally distributed plasmonic hot spots. Scripta Mater. 69:654-657. https://doi.org/10.1016/j.scriptamat. 2013.07.024

3. Khurgin JB, Boltasseva A (2012) Reflecting upon the losses in plasmonics and metamaterials. MRS Bull 37:768-779. https://doi. org/10.1557/mrs.2012.173

4. Zhang ZS, Yang ZJ, Liu XL, Li M, Zhou L (2010) Multiple plasmon resonances of $\mathrm{Au} / \mathrm{Ag}$ alloyed hollow nanoshells. Scripta Mater 63:1193-1196. https://doi.org/10.1016/j.scriptamat.2010.08.037

5. Yu YY, Chang SS, Lee CL, Wang CRC (1997) Gold nanorods: electrochemical synthesis and optical properties. J Phys Chem B 101:6661-6664. https://doi.org/10.1021/jp971656q

6. Garcia MA (2011) Surface plasmons in metallic nanoparticles: fundamentals and applications. J Phys D Appl Phys 44:283001283021. https://doi.org/10.1088/0022-3727/45/38/389501

7. Beck FJ, Mokkapati S, Catchpole KR (2010) Plasmonic lighttrapping for Si solar cells using self-assembled, $\mathrm{Ag}$ nanoparticles. Prog Photovoltaic: Res Appl 18:500-504. https://doi.org/10.1002/ pip. 1006

8. Siegel J, Lyutakov O, Rybka V, Kolska Z, Svorcik V (2011) Properties of gold nanostructures sputtered on glass. Res Lett 6: 96. https://doi.org/10.1186/1556-276X-6-96

9. Bahloul-Hourlier D, Perrot P (2007) Thermodynamics of the AuSi-O system: application to the synthesis and growth of siliconsilicon dioxide nanowires. J Phase Equilib Diffus 28:150-157. https://doi.org/10.1007/s11669-007-9023-Z

10. Ferralis N, Maboudian R, Carraro C (2008) Temperature-induced self-pinning and nanolayering of AuSi eutectic droplets. J Am Chem Soc 130:2681-2685. https://doi.org/10.1021/ja7101983

11. Ferralis N, el Gabaly F, Schmid AK, Maboudian R, Carraro C (2009) Real-time observation of reactive spreading of gold on silicon. Phys Rev Lett 103:256102. https://doi.org/10.1103/ PhysRevLett.103.256102

12. Ressel B, Prince KC, Heun S, Homma Y (2003) Wetting of Si surfaces by $\mathrm{Au}-\mathrm{Si}$ liquid alloys. J Appl Phys 93:3886-3892. https://doi.org/10.1063/1.1558996

13. Adachi T (2002) Eutectic reaction of gold thin-films deposited on silicon surface. Surf Sci 506:305-312. https://doi.org/10.1016/ S0039-6028(02)01429-2

14. Ruffino F, Romano L, Pitruzzello G, Grimaldi MG (2012) Hightemperature annealing of thin $\mathrm{Au}$ films on $\mathrm{Si}$ : growth of $\mathrm{SiO} 2$ nanowires or Au dendritic nanostructures. Appl Phys Lett 100:053102. https://doi.org/10.1063/1.3679614

15. Schuülli TU, Daudin R, Renaud G, Vaysset A, Geaymond O, Pasturel A (2010) Substrate-enhanced supercooling in AuSi eutectic droplets. Nature 464:1174-1177. https://doi.org/10.1038/ nature 08986

16. Mitlin VS (1993) Dewetting of a solid surface: analogy with spinodal decomposition. J Colloid Interface Sci 156:491-497. https://doi.org/10.1006/jcis.1993.1142

17. Ruffino F, Grimaldi MG (2015) Controlled dewetting as fabrication and patterning strategy for metal nanostructures. Phys Status Solidi A 212(8):1662-1684. https://doi.org/10.1002/pssa.201431755
18. Bischof J, Scherer D, Herminghaus S, Leiderer P (1996) Dewetting modes of thin metallic films: nucleation of holes and spinodal dewetting. Phys Rev Lett 77:1536-1539. https://doi.org/10.1103/ PhysRevLett.77.1536

19. Seemann R, Herminghaus S, Neto C, Schlagowski S, Podzimek D, Konrad R, Mantz H, Jacobs K (2005) Dynamics and structure formation in thin polymer melt films. J Phys Condens Matter 17: S267-S290. https://doi.org/10.1088/0953-8984/17/9/001

20. Qi WH (2005) Size effect on melting temperature of nanosolids. Physica B 368:46-50. https://doi.org/10.1016/j.physb.2005.06.035

21. Zhang M, Efremov MY, Schiettekatte F, Olson EA, Kwan AT, Lai SL, Wisleder T, Greene JE, Allen LH (2000) Size-dependent melting point depression of nanostructures: nanocalorimetric measurements. Phys Rev B 62:10548-10557. https://doi.org/10.1103/ PhysRevB.62.10548

22. Łapiński M, Synak A, Gapska A, Bojarski P, Sadowski W, Kościelska B (2018) New plasmonic platform for enhanced luminescence of valrubicin. Opt Mater 83:225-228. https://doi.org/10. 1016/j.optmat.2018.05.002

23. Gapska A, Łapiński M, Syty P, Sadowski W, Sienkiewicz JE, Kościelska B (2018) Au-Si plasmonic platforms: synthesis, structure and FDTD simulations. Beilstein J Nanotechnol 9:2599-2608. https://doi.org/10.3762/bjnano.9.241

24. Gentili D, Foschi G, Valle F, Cavallini M, Biscarini F (2012) Applications of dewetting in micro and nanotechnology. Chem Soc Rev 41:4430-4443. https://doi.org/10.1039/c2cs35040h

25. Thompson CV (2012) Solid-state dewetting of thin films. Annu Rev Mater Res 42:399-434. https://doi.org/10.1146/annurevmatsci-070511-155048

26. Trice J, Thomas D, Favazza C, Sureshkumar R, Kalyanaraman R (2007) Pulsed-laser-induced dewetting in nanoscopic metal films: theory and experiments. Phys Rev B 75:235439. https://doi.org/10. 1103/PhysRevB.75.235439

27. Ruffino F, Grimaldi MG (2014) Self-organized patterned arrays of $\mathrm{Au}$ and $\mathrm{Ag}$ nanoparticles by thickness-dependent dewetting of template-confined films. J Mater Sci 49:5714-5729. https://doi. org/10.1007/s10853-014-8290-4

28. Zhang M, Wen JE, Efremov MY, Olson EA, Zhang ZS (2012) Metastable phase formation in the Au-Si system via ultrafast nanocalorimetry. J Appl Phys 111:093516. https://doi.org/10. $1063 / 1.4712342$

29. Jany BR, Gauquelin B, Willhammar T, Nikiel M, van den Bos KH, Janas A, Szajna K, Verbeeck J, van Aert S, van Tendeloo G, Krok F (2017) Controlled growth of hexagonal gold nanostructures during thermally induced self-assembling on Ge(001) surface. Sci Rep 7: 42420. https://doi.org/10.1038/srep42420

Publisher's Note Springer Nature remains neutral with regard to jurisdictional claims in published maps and institutional affiliations. 